\title{
6. Heines Aufenthalte in Seebädern und Kurorten
}

$\begin{array}{lll}1825 & \text { August, September } & \text { Norderney } \\ 1826 & \text { Juli, August } & \text { Norderney } \\ 1827 & \text { Juni } & \text { Brighton } \\ & \text { Juli } & \text { Margate } \\ & \text { August } & \text { Ramsgate, ostfriesische Inseln } \\ 1829 & \text { August, September } & \text { Helgoland } \\ 1830 & \text { Juli, August } & \text { Helgoland } \\ 1831 & \text { August, September } & \text { Boulogne sur Mer } \\ 1832 & \text { August, September } & \text { Le Havre } \\ 1833 & \text { August, September } & \text { Boulogne sur Mer } \\ 1834 & \text { Juli, August } & \text { Boulogne sur Mer, Dieppe } \\ 1835 & \text { August, September } & \text { Boulogne sur Mer } \\ 1836 & \text { Oktober } & \text { Marseille } \\ 1837 & \text { Juni, Juli } & \text { Granville } \\ & \text { August } & \text { Boulogne sur Mer, Le Havre } \\ 1838 & \text { August, September } & \text { Granville } \\ 1839 & \text { Juni, Juli, August } & \text { Granville } \\ 1840 & \text { August, September } & \text { Granville } \\ 1841 & \text { Juni, Juli, August } & \text { Cauterets } \\ 1842 & \text { August } & \text { Boulogne sur Mer } \\ 1843 & \text { Juli, August } & \text { Trouville } \\ 1845 & \text { Juni bis Oktober } & \text { Montmorency, Enghiens-les-Bains (Schwefel) } \\ 1846 & \text { Juni, Juli, August } & \text { Barèges }\end{array}$

